\title{
América Latina frente a la crisis de 1929*
}

Diana Guillén

Frente a la idea de que la crisis del 29 jugó en la región un papel protagónico, se propone que dicho fenómeno fue, en todo caso, un acelerador de procesos estructurales iniciados en el área desde tiempo atrás.

os efectos de la crisis que en 1929 sacudió a la economía mundial fueron más allá del nivel meramente cuantitativo, y si bien sus orígenes inmediatos tenían que ver con la forma en que se reorganizó el mundo después de la gran guerra, y podian, en esencia, ser circunscritos al campo de las políticas económicas adoptadas, ${ }^{1}$ las conse-

\footnotetext{
- Las ideas centrales de este trabajo se presentaron en la mesa redonda América Latina y Estados Unidos de Norteamérica en la crisis del 29 , celebrada en este instituto en noviembre de 1989.

1 Aunque es claro que la primera guerra mundial marcó profundamente no sólo a los países que se vieron involucrados en ella de manera directa y que la recesión en que la economía internacional se vio sumida al iniciarse la década de los treinta está en buena medida
}

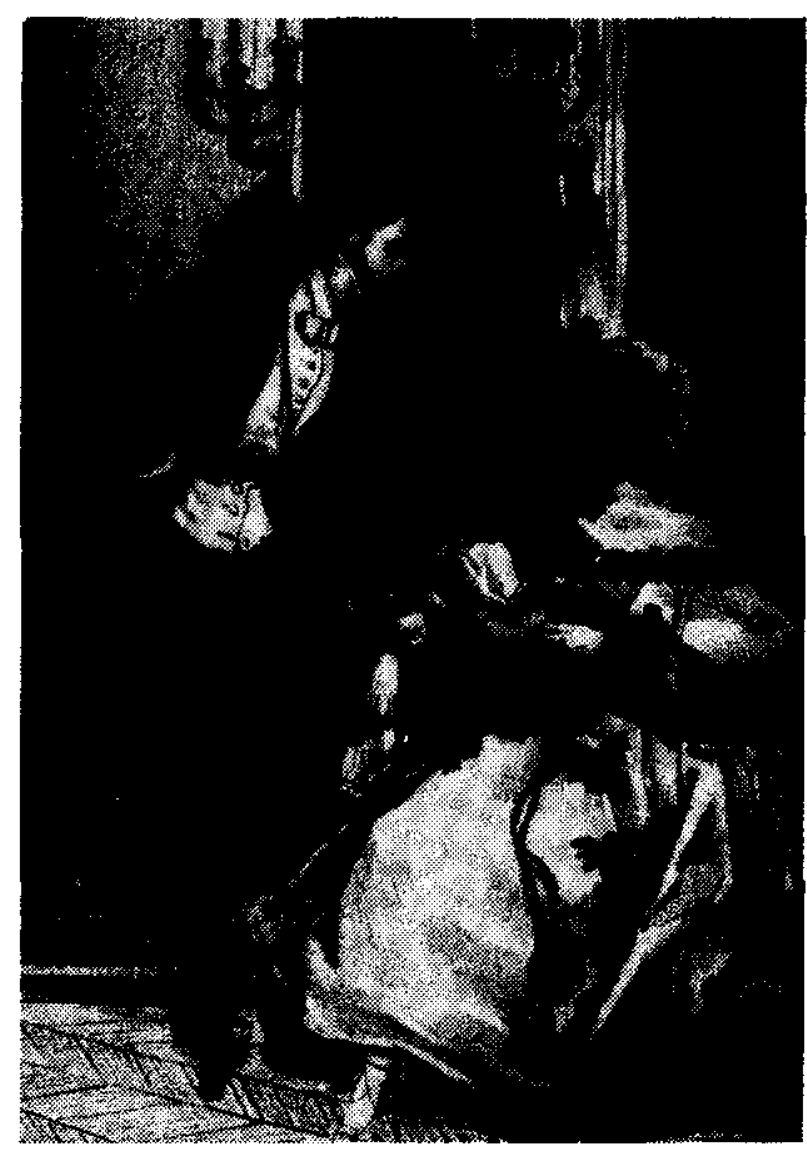


cuencias de lo que aparentemente constituía un simple desajuste financie-ro, ${ }^{2}$ incidieron también en una serie de cambios vividos por la sociedad norteamericana que, aun cuando mantuvo sus patrones de acumulación y los criterios a partir de los cuales se relacionaban sus integrantes, durante ese periodo fue testigo del reacomodo que escenificaron grupos enteros. Las leyendas de fortunas que se desmoronaban mientras otras tantas emergían y la imagen de los financieros vendiendo manzanas en las calles aledañas a Wall Street, quizá han sido mitificadas por la producción cinematográfica sobre la época, sin embargo, es un hecho que tales dramatizaciones tuvieron como base el desajuste que en términos sociales significó la crisis. En otras palabras, la recesión no sólo implicó que se desplomaran

asociada con el desenlace que tuvo dicho conflicto, el crack que en 1929 sacudió a Estados Unidos y que en mayor o menor medida se fue extendiendo al resto del mundo, debe entenderse también como el resultado de una tendencia estructural, cuyo origen se remonta al siglo xrx. En palabras de Aldcroft, "no podemos decir que la depresión de 1929-1932 la causara la guerra y nada más que la guerra, ni podemos descartar ésta diciendo que no repercuti6 en la crisis del capitalismo en el periodo de entreguerras", Derek H. Aldcroft, Historia económica mundial del siglo XX. De Versalles a Wall Street, 1919-1929, Crítica, Barcelona, 1985, p. 15.

${ }^{2}$ Al desplomarse la Bolsa de Valores de Nueva York en octubre de 1929 terminaba toda una época de bonanza económica y de especulación financiera que hasta ese momento parecia no conocer limite alguno. El optimismo generalizado que precedió al derrumbe se mantuvo incluso una vez iniciado éste y para algunos los acontecimientos representaron sólo una actitud de pánico momentáneo que había atacado a los inversionistas de la ciudad de Nueva York y de la que no debian por lo tanto esperarse repercusiones a largo plazo. Cfr. John K. Galbraith, El crack del 29, Ariel, Barcelona, 1983. la productividad, los precios, las tasas de ganancia, las posibilidades de empleo $o$, en fin, cualquier otro de los indicadores que normalmente se utilizan para documentarla; además de todos estos aspectos, también incidió de manera directa en la vida cotidiana de quienes la padecieron. $^{3}$

De hecho, en uno de los pocos espacios en que la primera guerra mundial lejos de implicar devastación había traído beneficios, el país más rico del orbe, en el que se creía que la prosperidad no tendría límites, entre 1930 y 1932 todos los sectores, desde los granjeros hasta los profesionistas, pasando por los trabajadores y los pequeños y grandes empresarios, vieron cómo dicha prosperidad se derrumbaba y cómo, mientras en las grandes ciudades la gente

'La crisis de 1929, como cualquier otra, significó grandes pérdidas para la economia en su conjunto y cambió los patrones de vida de quienes prácticamente de la noche a la mañana despertaron empobrecidos y sin mayores posibilidades de mejorar su situación, o bien, de quienes encontraron en la coyuntura la posibilidad de enriquecerse. Para la mayoria la recesión llegó tiempo después del crack financiero, cuando se cerraron las fábricas, se perdieron los trabajos y no había bancos a los cuales recurrir, ya que, a pesar de las fantasias que circulan al respecto, no cualquiera poseía un paquete de acciones y por lo tanto no toda la población sintió en un primer momento la caída de éstas. Como señala Adams, "El alza de las cotizaciones fascinaba a una nación obsesionada con las estadisticas del mismo modo que lo estaba por las estadisticas que se derivaban de los resultados de los encuentros de beisbol", pero en el fondo y aun cuando todo el mundo hablaba del tema y circulaban toda clase de rumores sobre las fortunas adquiridas en la bolsa, rumores apoyados por la aparente imposibilidad de perder dinero en ella, quienes participaron del juego siguieron siendo pocos, Willi Paul Adams (comp.), Los Estados Unidos de América, Siglo XXI, México, 1984, p. 286 (Colección de Historia Universal, núm. 30). 
deambulaba por las calles en busca de un empleo que no lograba conseguir, en el campo las cosechas se acumulaban al tiempo que los precios descendían. ${ }^{4}$ Los costos de la crisis fueron, pues, bastante concretos en el terreno vivencial de personas con nombre y apellido que, más allá de las estadísticas, ${ }^{5}$ sintieron en carne propia el proceso depauperizador. ${ }^{6}$

Esta faceta de la depresión económica puede recuperarse a través de los testimonios que los actores de la misma han dejado desperdigados y que de alguna manera ayudan a recrear el ambiente general de la época. Así, pasajes como los que a continuación reproducimos de la Autobiografia de Arthur Miller, además de dar cuenta de las dimensiones que adquirió la crisis, nos muestran el sentir que la misma dejó en buena parte de la sociedad norteamericana.
${ }^{4}$ Cfr. Leo Huberman, Historia de los Estados Unidos, nosotros el pueblo, Nuestro Tiempo, México, 1984, p. 342.

"Si hacemos hincapié en la dimensión humana de la crisis es porque algunas veces se privilegian los desastres económicos traducidos a números y se dota 2 éstos de vida propia olvidando que su sentido sólo puede encontrarse en relación con las personas. Sin embargo, esta postura no equivale a desechar la cuantificación de lo sucedido, ya que, para entender lo que pasó con la economia en su conjunto, sigue siendo necesario remitirse a las fuentes estadisiticas.

- Si bien la tendencia que predominó en la época puede ser resumida en una sola palabra: pobreza, resulta importante aclarar que ésta no atacó a todos de manera homogénea y que por el contrario se resintio a partir de criterios diferenciados. Mientras para algunos los ahorros se desvanecían con el cierre de los bancos, para otros la riqueza basada en la especulación se desplomaba y para otros más implicaba el fin de sus industrias y comercios. Quienes resultaron más afectados, resintieron esta disminución generalizada en el nivel de vida a través de situaciones de hambre y hacinamiento. $C f r$. Leo Huberman, $o p$. cit., pp. 342-344.
Se ha dicho con frecuencia que lo que evitó una revolución en Estados Unidos durante lo más negro de la Depresión fue la buena voluntad con que los norteamericanos se culparon a sí mismos de la catástrofe en vez de culpar al sistema. Una leve pátina de culpabilidad recayó sobre los hombros de los padres afectados, para una cantidad ignorada de los cuales no volvería a haber recuperación alguna de la dignidad y confianza, sólo una interminable muerte en vida que proseguiría hasta el final. Ya a comienzos de los años treinta, cuando la catástrofe contaba con un par de años de existencia, los periódicos decían que sólo en la ciudad de Nueva York habia cerca de 100000 personas tan afectadas psicológicamente que probablemente serían incapaces de volver a trabajar. Y no sólo era cuestión de escasez de comida; era la esperanza lo que les había abandonado, la ilusión vital y la capacidad de volver a tener fe. Norteamérica, como diría Archibald Mac Leish, era una serie de promesas, y para algunos, la crisis económica, en el sentido más profundo, fue una promesa rota. ${ }^{7}$

Las reflexiones del dramaturgo son sin duda producto de la atmósfera que rodeó su adolescencia y que él padeció en el terreno familiar:

Tenía pues dos padres, el auténtico y el figurado, y me resentía del segundo por no saber salir del descalabro general. Junto con deseos de ayudarle, sentí compasión por él cuando primero se eliminó al chofer, luego al National de siete plazas y más tarde al bungalow de veraneo, y comenzó la espera del regreso del pasado y la irrealidad del presente nos envolvió como una enredadera llena de polvo que hubiera arraigado en la alfombra de la sala de estar y cuyo incontenible

7 Arthur Miller, Vueltas al tiempo. Autobiografia, Tusquets Editores, Barcelona, 1988, p. 116 (Colección Andanzas, 78). 
- crecimiento tuviera que frenarse día tras día. Sin quejarse nunca ni comentar siquiera sus problemas económicos, mi padre se iba hundiendo cada vez más en el silencio, sus siestas se hacían cada vez más prolongadas y su boca parecía haberse secado. $^{8}$

\section{Y en el terreno social:}

Todo era muy sencillo: nadie tenía dinero. El que sería el último gobierno republicano en el curso de dos décadas estaba a punto de recibir el finiquito, sin ideas, y para nosotros como si dijéramos en el cubo de la basura, falto incluso de la retórica de la esperanza. Los recuerdos que tengo de aquel año en particular [1932], de cuando me desplazaba con el carnión por las calles, cruzaba los puentes, subía al Bronx, salía hasta Brooklyn, me configuran una ciudad fantasma que poco a poco se iba cubriendo de polvo, manzana tras manzana, cada vez con más rótulos de SE TRASPASA en sucios escaparates de tiendas y talleres abiertos muchos años antes y en la actualidad cerrados. Fue también el año de las colas en las panaderías, de hombres sanos y robustos que se formaban en batallones de seis y ocho en fondo a lo largo del muro de algún almacén, en espera de que este $o$ aquel organismo municipal improvisado, o el Ejército de Salvación, o cualquier iglesia, les diese un tazón de caldo o un panecillo.?

En las descripciones de Miller están presentes las dos grandes caras de la crisis que aquí nos interesa resaltar: la objetiva, que nos habla de la pobreza y las dificultades a las que se enfrentaron en mayor o menor medida los norteamericanos, y la subjetiva que nos remite a los sentimientos de angustia y desesperanza

\footnotetext{
Ibid., pp. 114-115.
}

' lbid, p. 209. que por mucho tiempo se apoderaron de sus conciencias.

En este contexto no es de extrañar que el paisaje que presentaba Estados Unidos una vez controladas las tendencias recesivas distara mucho de aquel que había privado durante el periodo de auge. La incertidumbre que siguió al optimismo de la década anterior se justificaba en los ámbitos individual y social y las opciones para lo que parecía ser un callejón sin salida resultaban difíciles de encontrar. En medio de tal ambiente, la necesidad de cambiar las líneas por las que hasta entonces se había encaminado el desarrollo económico se volvía incontrovertible; después de todo, la crisis de 1929 había superado con mucho a las anteriores y había dejado huellas indelebles en la memoria colectiva de los norteamericanos.

Quedaba la incógnita de hacia dónde debería dirigirse el numbo y la respuesta se buscaba planteando una nueva relación entre el Estado y la sociedad, relación a partir de la cual, se dejaban de ladolos principios liberales y se adoptaba una política interventora que ponía en las manos del aparato gubernamental la reactivación económica del país. Si bien el llamado New Deal que encabezó Roosevelt no constituyó una revolución, ni atentó contra las bases del sistema en que se originaba, significó un profundo cambio histórico, cuyo principal rasgo fue la responsabilidad que se depositaba en el gobierno para la rectoría de los asuntos económicos y, sobre todo, para el mantenimiento del nivel de vida de la población. ${ }^{10}$

${ }^{10}$ Aunque podría pensarse que en la tercera década del siglo $x x$ era evidente que el laissez 
Así pues y con base en todo lo que hasta aquí se ha expuesto, podemos pensar que uno de los procesos que más importancia tuvo para Estados Unidos durante el periodo de entreguerras fue el que se inició en 1929 al caerse la Bolsa de Valores de Nueva York. Aunque de manera muy sumaria, hemos intentado resaltar dicha trascendencia, ya que nos parece que dado el carácter mundial que adquirió la recesión económica, la historia de otros paises se ha interpretado en función de la experiencia norteamericana. Parecería que el punto de partida es que la crisis desestructuró a todos por igual y que ya se tratara de países industrializados, ya de productores de materias primas, cada uno reprodujo el mismo patrón."

\footnotetext{
faire-laissez passer propio del capitalismo decimonónico necesitaba ajustes acordes con la nueva realidad que se vivía, Estados Unidos se encontraba demasiado ensimismado con su prosperidad y con su acelerado desarrollo interno como para captarlo. En estas condiciones, la tendencia recesiva que se inició en 1929 propició también un replanteamiento del sistema de valores imperante y se tomaron medidas que rompian con las concepciones económicas, políticas y sociales que hasta entonces dominaron la escena. Las tres $R$ implicadas en el New Deal (relief, recuperation, reform) incorporaron de lleno a la acción estatal en orbitas que antes le estaban vedadas y más allá de lo novedosas que pudieran ser las tareas concretas que se emprendieron (algunas de ellas hacía tiempo que se practicaban en países como Alemania e Inglaterra), representaron en general el descenso del liberalismo clásico. Cfr. Willi Paul Adams, op. cit., pp. 305-323, y Leo Huberman, op. cit., pp. $360-430$.

${ }^{17}$ En general se ha aceptado acríticamente que en todos lados la crisis tuvo repercusiones profundas y a partir de esta premisa se han buscado sus manifestaciones en cada caso. Este hecho ha significado que, por lo menos en América Latina, la mayor parte de los cambios que tuvieron lugar a partir de la década de los treinta se interpretan como un epifenómeno de la depresión económica
}

A estas alturas creemos que es importante repensar esta idea, ya que si bien al término de la primera guerra mundial Estados Unidos había desbancado a Inglaterra y había adquirido un papel protagónico en el contexto cconómico internacional, convirtiéndose entre otras cosas en el principal acreedor de las naciones occidentales, ${ }^{12}$ los sucesos posteriores a 1929 y las características que en cada país adquirió la crisis variaron en función de la historia particular de los involucrados.

Podrá argumentarse que las cifras de la época demuestran el predominio que ejercía la economía norteamericana sobre el resto, ${ }^{13}$ y que por lo tanto, los tambaleos de ésta necesariamente tenían que repercutir en sus subordinadas. Sin embargo, y aunque en un sentido gene-

mundial, sin importar si los mismos venían gestándose desde tiempo atrás.

${ }^{12}$ Resulta interesante destacar el giro de $180^{\circ}$ que en este sentido dio Estados Unidos, a quien después de ser un país deudor, en 1918 se le tenian que pagar 7000000 de dólares por concepto de deudas de guerra, cantidad a la que ese mismo año se sumaron otros 3300000 que necesitaban las naciones europeas para su reconstrucción. Cfr. Willi Paul Adams, op. cit, p. 259.

${ }^{13}$ En 1929, 45\% de la producción industrial del mundo correspondía a Estados Unidos, quien además invirtió en el extranjero e importó mercancias por un total de 7400000000 de dólares (entre ambos rubros) y acaparó $12.5 \%$ de las importaciones mundiales. En 1932, al tiempo que los capitales norteamericanos se repatriaban masivamente, esta demanda disminuyo en un $32 \%$ (a 5000000 de dólares), lo que evidentemente repercutio en la economí mundial. En realidad el volumen global de los intercambios comerciales no se fue tan abajo, lo que sucedio fue que los precios, sobre todo de los productos agricolas y de las materias primas, sufrieron una vertiginosa caída. Cfr. Maurice Niveau, Historia de los becbos económicos contemporáneos, Ariel, Barcelona, 1983, pp. 188-189. 
ral el planteamiento es válido, se pierden en él las mediaciones que seguramente se dieron en los casos específicos y que desde nuestro punto de vista ayudarían a recuperar las tendencias estructurales internas que también estuvieron presentes en la crisis de 1929. En esencia pues, se trata de verel proceso recesivo mundial no sólo en función de lo que acontecía en Estados Unidos, a pesar de la importancia que éste tuvo para el mismo, sino como una combinación en la que a los factores provenientes del exterior se aunaban las características propias de cada país. Así, aunque en todos los casos se repetían ciertos problemas como consecuencia de la depresión, las repercusiones que éstos tuvieron y la forma en que se trató de enfrentarlos variaron entre un lugar y otro. ${ }^{14}$

Para América Latina en su conjunto la década de los treinta fue un periodo de cambios entre los que sin duda hay que considerar los serios desajustes vividos en el terreno económico. Al deterioro de los términos de intercambio y a la contracción en el volumen de importaciones, se aunó un nuevo destino para la inversión extranjera que dejó de inclinarse por las exportaciones tradicionales $y$ prefirió dedicarse a las nacientes industrias, y un incremento de los egresos destinados al servicio de la deuda. ${ }^{15}$

${ }^{14}$ Carlos F. Díaz Alejandro, "América en los años treinta", en Rosemary Thorp (comp.), América Latina en los años treinta, el papel de la periferia en la crisis mundial, Fondo de Cultura Económica/Economia latinoamericana, México, 1988, pp. 33-34.

" Desde 1931 se inició el cese de los pagos por dicho concepto y para 1934 sólo Argentina, Haití y República Dominicana mantenían el servicio normal de su deuda externa. Carlos F. Díaz Alejandro, op. cit., pp. 34-35.
Todos estos elementos pusieron a las economías latinoamericanas en serios problemas que, es importante recalcarlo, no se circunscribían al ámbito privado y afectaban también la situación de las finanzas públicas. ${ }^{16}$ Así pues, era claro que dada la posición que ocupaban los países latinoamericanos en el contexto internacional, ${ }^{17}$ las tendencias recesivas imperantes en los países centrales a partir de 1929 también les habían llegado a ellos.

El paradigma que tradicionalmente se ha manejado para explicar esta parte de

${ }^{16}$ Como dice Halperin, "aún sin ubicar entre los urgentes el problema de la deuda pública acumulada entre 1918 y 1930 , que es en casi todas partes muy cuantiosa (en algunos paises, como Perú, es abrumadora), la crisis con solo hacer desaparecer en lo inmediato la posibilidad de recurrir nuevamente al mercado financiero mundial, crea a la finanza pública una situación casi tan grave como la de la economía", Tulio Halperin, Historia contemporánea de América Latina, Alianza, Madrid, 1981, p. 360 (Colección El libro de bolsillo, 192). Carmagnani por su parte considera que en Latinoamérica la consecuencia más importante de la crisis fue que los gobiernos latinoamericanos ya no pudieron hacerse de recursos adicionales en los mercados monetarios exteriores. Marcello Carmagnani, Estado y sociedad en América Latina, Grijalbo, 1984, p. 198 (Colección Crítica).

${ }^{17}$ Más allá de las discusiones que se han dado entre los latinoamericanistas sobre las implicaciones que traen consigo conceptos como periferia, subdesarrollo o dependencia, lo que la historia demuestra es que nuestra evolución es diferente a la seguida por los países centrales, por llamarlos de alguna manera, y que aun si consideramos que unos y otros son complementarios desde una perspectiva global, las relaciones que desde sus inicios se plantearon entre ambos estuvieron marcadas por la desigualdad. En estas condiciones, es innegable que párte de la trayectoria latinoamericana sólo puede entenderse, gústenos o no, si se consideran fenómenos y procesos que en estricto sentido le son ajenos o por lo menos no son producto de la evolución interna seguida por cada país. 
nuestra historia se originó en gran medida dentro del pensamiento "cepalino" y hace hincapié en el proceso de sustitución de importaciones que impulsó la crisis al privar a los capitales nacionales y extranjeros de buena parte de sus fuentes de ingreso. Hasta antes de 1929, de acuerdo con esta visión, América Latina se había dedicado a exportar materias primas y productos agrícolas que, al colocarse en el mercado internacional, permitían obtener divisas con las que además de realizarse las importaciones necesarias, se pagaba la deuda pública y privada. Así pues y dentro de la misma óptica, la brusca caída en los precios de las mercancías sobre las que descansaban las diversas economías nacionales obligó a cambiar el rumbo, no sólo porque demostró las desventajas de depender exclusivamente de un producto, sino porque hizo necesaria la producción de lo que ya no podía adquirirse en el exterior. ${ }^{18}$

En abstracto la explicación parece plausible, sobre todo porque si se revisa

19 Aunque existen diferencias y matices entre los diversos autores que han escrito sobre el tema, el punto que en en general ha unido al pensamiento latinoamericano con respecto al proceso industrializador iniciado en algunos países despues de 1929, es el que aquí se ha expuesto de manera muy esquemática. Cfr. F.H. Cardoso y Enzo Faletto, Dependencia y desarrolloen América Latina, Siglo XXI, México, 1977; Marcello Carmagnani, op. cit.; Antonio García, El proceso bistórico latinoamericano, Nuestro Tiempo, Mexico, 1979; Sergio de la Peña, El antidesarrollo de América Latina, Siglo XXI, México, 1981; Pablo González Casanova (coord.), América Latina en los años treinta, UNAM-Instituto de Investigaciones Sociales, México, 1977; Tulio Halperín Donghi, op. cit.; Ruy Mauro Marini, Subdesarrollo y rewolución, Siglo XXI, México, 1977; Octavio Rodríguez, La teoría del subdesarrollo de la CEPAL, Siglo XXI, México, 1981. la historia continental se encontrará que, en efecto, los precios de las materias primas bajaron, que la disponibilidad de recursos se contrajo, ${ }^{19}$ y que en las década de los treinta algunos países iniciaron el camino hacia la industrialización. Sin embargo, si se la contrasta con la realidad y se considera la necesidad de que hablábamos líneas arriba de rescatar las tendencias nacionales, ciertos problemas harán su aparición: en primer lugar, cuando se deja el cuadro de conjunto y se analizan los casos concretos, salta a la vista que no en todos la recesión tuvo la misma intensidad ni se dio al mismo tiempo. ${ }^{20}$

En segundo término, habría que considerar que la caída en el rubro de las importaciones no se debió sólo a la crisis como tal, ya que también intervino en ella la recuperación de los países europeos después de la guerra, los cuales empezaron a producir algunas de las cosas que antes compraban en el exterior. Una tercera observación tendría

${ }^{19} \mathrm{Y}$ no sólo porque disminuyeron los ingresos provenientes de las exportaciones, sino también porque se cerraron las opciones para obtener dinero fresco en el exterior.

20 Además de que países como Argentina, Brasil y Colombia resintieron desde mediados de 1928 los efectos del ascenso de la Bolsa de Valores de Nueva York y el consecuente encarecimiento del dinero, o que los problemas de Cuba dataran de 1925, mientras que los de Honduras empezaron hasta 1932 (Cfr. Charles P. Kindleberger, "La depresión mundial de 1929 en América Latina vista desde afuera", en Rosemary Thorp, comp., op. cit., pp. 362-364), nos queda la duda de lo que sucedió en aquellas economías que en mayor o menor medida se basaban en unidades agrarias de autosuficiencia y donde la caída de los precios de los productos que se ofrecian en el mercado mundial afectó sin duda las finanzas locales, pero donde, también, siempre había la posibilidad de regresar a cultivar la parcela. 


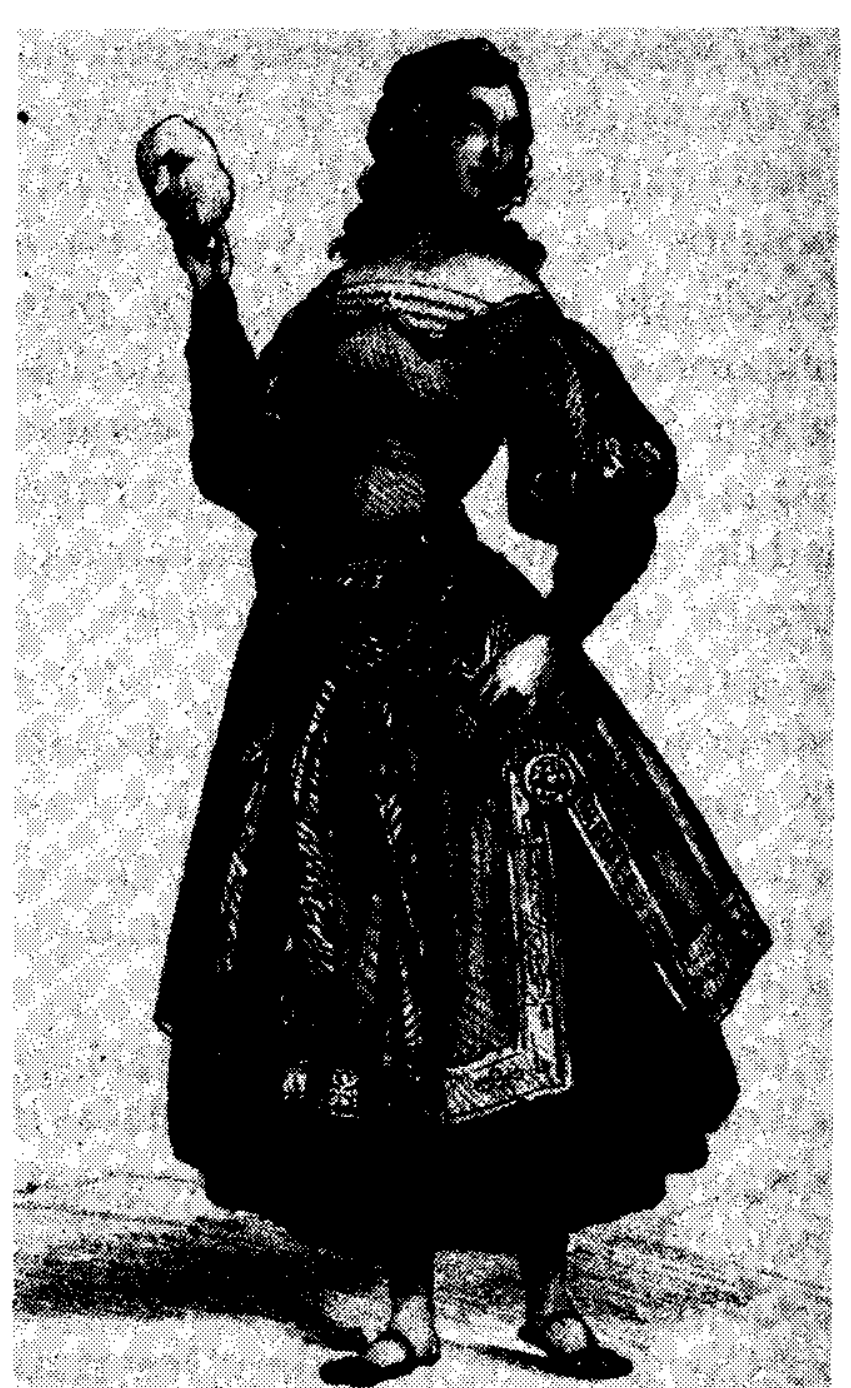

que ver con las fluctuaciones que, como resultado del juego del mercado, desde antes de 1929 se venían dandoen los precios de las materias primas y de los productos agropecuarios y que en algunos casos dificultaban establecer linealmente la relación entre su caída y la crisis. Por último está el tema de la sustitución de importaciones, proceso que no creemos deba asociarse exclusivamente con la crisis; en realidad, fueron sólo algunos países los que tuvieron la capacidad estructural para iniciar el camino industrializador, camino que tiene por lo tanto más relación con lo acontecido antes de 1929 que con la coyuntura iniciada ese año. $^{21}$

\footnotetext{
${ }^{21}$ Agust in Cueva, El desarrollo del capitalismo en América Latina, Siglo XXI, México, 1982; Rosemary Thorp (comp.), op. cit.
}

En síntesis, no discutimos que al despuntar la década de los treinta los países latinoamericanos vivieron ciertos cambios económicos, ni que para entender éstos sea necesario considerar que la economía mundial, en su conjunto, pasaba por una seria recesión. Sin embargo, nos cuestionamos sobre la intensidad que a veces se les ha atribuido a dichos cambios y sobre la causalidad unilineal con la que se ha explicado su origen. Creemos que los peros que se le pueden poner a las interpretaciones de lo sucedidoque han predominado, tienen que ver sobre todo con dos cuestiones: primero, la dificultad real de acercarse a un objeto de estudio tan heterogéneo como América Latina, el cual no se presta al establecimiento de afirmaciones generales. $Y$, segundo, la tendencia a analizar la crisis de 1929 a la luz de lo que pasó en Estados Unidos, donde, como veíamos, se trastocaron desde la economía hasta los valores sociales.

En otras palabras, parecería que las reflexiones que han surgido se basan sobre todo en la experiencia de algunos países (Argentina, Brasil y México son generalmente una de las referencias obligadas) que, dado que van a la cabeza del desarrollo dentro del subcontinente, se convirtieron en foco de interés para los analistas y pasaron a ser una especie de muestra de la cual, aun cuando pudiera no ser representativa, salieron la serie de hipótesis generales que ya conocemos. Aunado a este problema, que no es por cierto exclusivo de los análisis sobre la recesión, habría que meditar sobre la forma en que se han interpretado esos casos paradigmáticos y establecer si la crisis iniciada en Estados Unidos en 1929 efectivamente jugó allí o en otros lugares 
el papel de parteaguas que se le ha asignado.

Nos inclinaríamos a pensar que la profundidad que adquirió la recesión en el norte del continente llevó a buscar efectos similares en el sur y que, como la realidad, por lo menos la de aquellas sociedades de las que más datos se poseían, mostró los deterioros y cambios ya descritos, éstos fueron achacados a la crisis, al mismo tiempo que se hizo girar la interpretación del periodo en torno a ella. Fue en este contexto que a nuestro parecer se dejaron de lado aquellos elementos que habían ido tejiendo los países latinoamericanos a lo largo de su historia $y$, se olvidaron también las diferencias que, como producto de la misma, existían entre ellos; así se postularon hipótesis que al sostener un eje explicativo externo borraron de golpe las tendencias estructurales y las mismas especificidades propias de cada caso.

Así pues, y a pesar de que valoramos los serios esfuerzos que se han dirigido a rescatar lo que de conjunto tiene la historia de América Latina, nos parece que la única forma de entender ésta es desde la diversidad y que para medir los efectos que la crisis de 1929 tuvo sobre nuestras economías, se necesita volver la mirada hacia las experiencias nacionales y revisar las relaciones que se establecieron entre las olas recesivas externas y las tendencias de larga duración internas. ${ }^{22}$ Por lo demás, diríamos que

22 Esto por supuesto implicaria cambiar el punto de partida de las investigaciones a realizar sobre el tema y, más que nada, implicaría un arduo trabajo de revisión de viejas y nuevas fuentes. Por otro lado y dependiendo del grado de diversidad ésta es la mejor manera de explicar los diferentes caminos que antes y después de 1929 han tomado las economías latinoamericanas, ya que, si se acepta la hipótesis de que independientemente de su historia particular la depresión de los países centrales afectó a todos por igual y produjo respuestas similares, se homologa un proceso cuyos heterogéneos resultados son evidentes hoy.

En el terreno político también nos gustaría revisar la interpretación del periodo que se ha utilizado con mayor frecuencia y que se advierte tanto en las obras de carácter general como en los estudios de caso. De hecho y por más que trabajos como el que coordinó Pablo González Casanova en 1977, avancen en el rescate de las peculiaridades nacionales y ofrezcan, por lo tanto, elementos que dan cuenta de la larga data y de la complejidad que rodearon las relaciones políticas y sociales imperantes en nuestros países durante la década de los treinta, ${ }^{23}$ la idea que se mantiene como eje y sirve de base para el análisis general, establece una relación causal directa entre los desajustes políticos de la época y los tropiezos en los que se vieron envueltas las diversas economías nacionales. ${ }^{24}$

Por ello, en las periodizaciones de la historia política latinoamericana se ha tendido a marcar 1930 como un año de

que asumió el proceso en cada pais, tal vez obligaria a desechar 12 idea de que hubo una tendencia general aplicable a toda el área.

23 Pablo González Casanova (coord.), op. cit.

${ }^{24}$ Esta inclinación 2 interpretar los fenómenos políicos a la luz de lo que acontece con la economia, en algunos casos tiene que ver con la tradición marxista que coloca a los elementos superestructurales en un plano de dependencia con respecto a su base económica. 
corte, en el que, debido a la recesión económica, el estado oligárquico se derrumbaba. La tesis central que se ha manejado habla de la desestructuración que sufrieron los sectores dominantes al caerse las exportaciones y de la merma que en este sentido se generó alrededor de su poder, hecho que, aunado a la aparición y crecimiento de nuevos sectores y a la exacerbación de los problemas en los ya existentes, redundó en una transformación de la forma estatal predominante. ${ }^{25}$ Nosotros plantearíamos una tesis alternativa: ${ }^{26}$ a pesar de que la década de los treinta efectivamente constituyo un periodo políticamente inestable en el que los cambios de gobierno

${ }^{25}$ Cfr. Marcello Carmagnani, op. cit., pp. 293300; Pablo Gonźlez Casanova (coord.), op. cit.; Octavio Ianni, La formación del estado populista en América Latina, Era, México, 1980, pp. 84-94 (Serie Popular Era, 30); Sergio de la Peña, op. cit., pp. 161-171.

${ }^{26}$ Nuestras ideas sobre las transiciones políticas que tuvieron lugar en la Epoca y su relación con la crisis económica, son producto de un

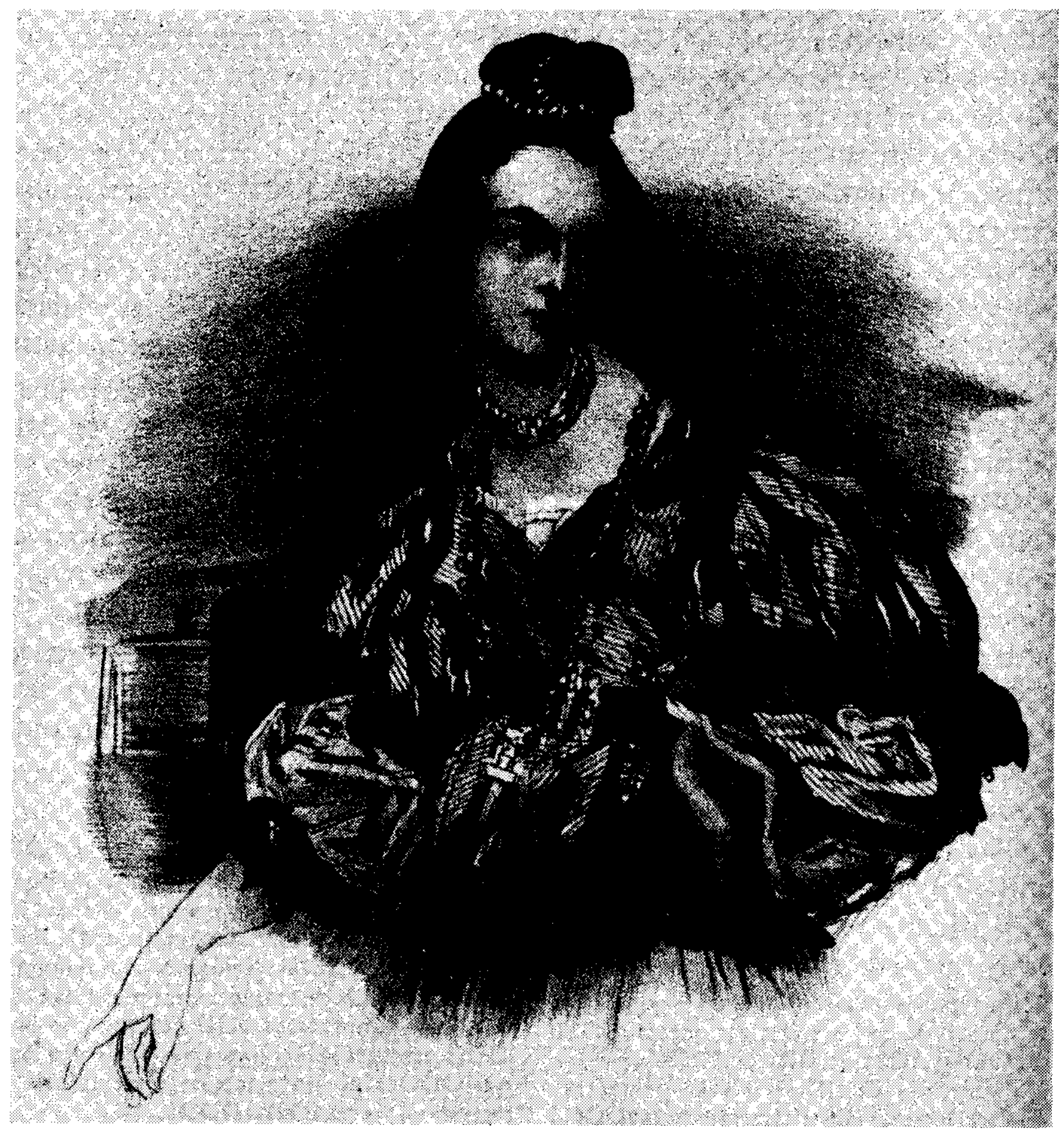




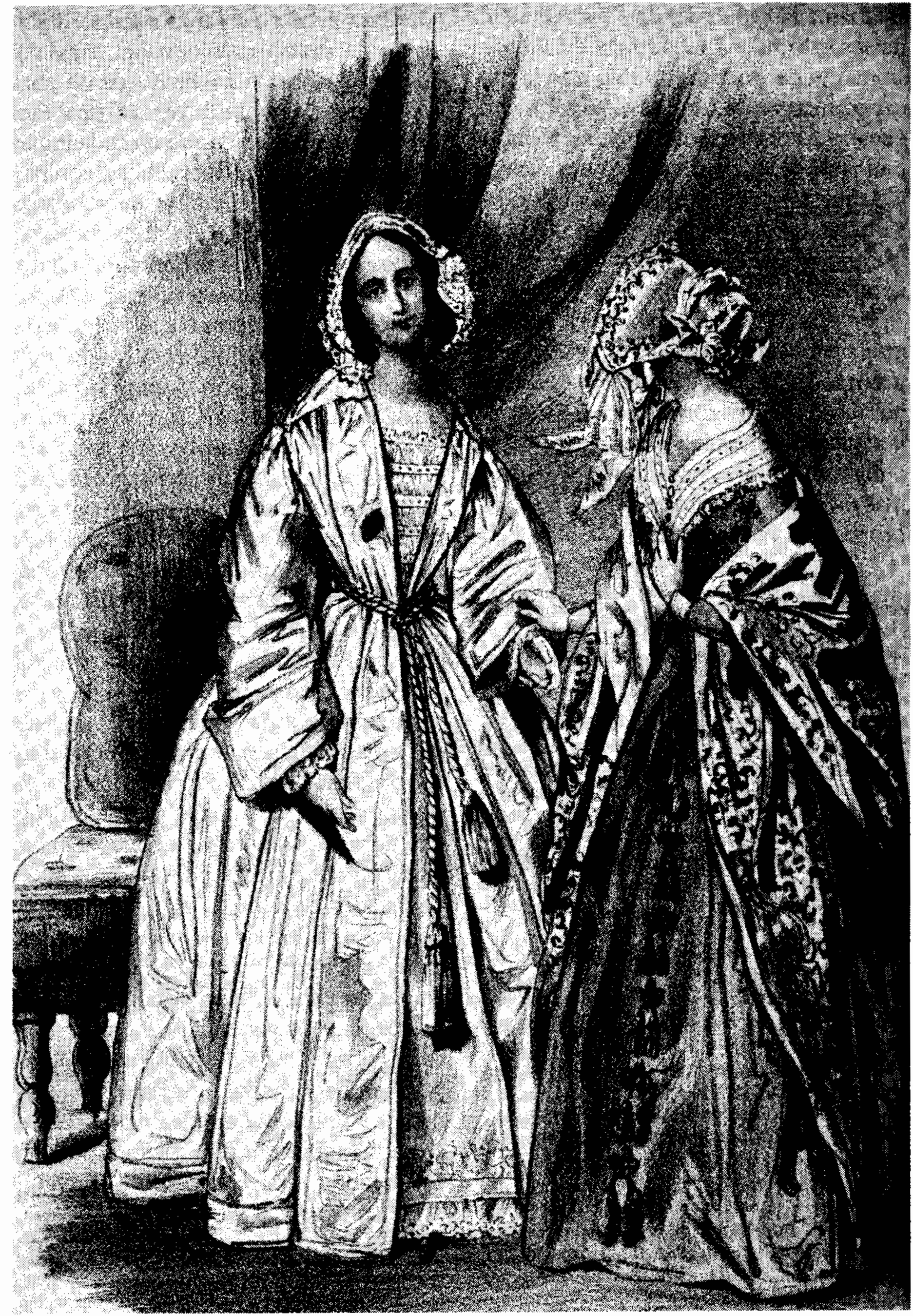


estaban a la orden del día, ${ }^{27}$ en los siete países estudiados las formas de Estado se mantuvieron y quizá sólo con la excepción de Brasil, donde el movimiento encabezado por Getulio Vargas inició una serie de transformaciones antioligárquicas, el Estado que en cada caso se había conformado antes de la crisis, fue aquel que siguió su camino después de ella. ${ }^{28}$

En este sentido vale la pena señalar que para el periodo que nos ocupa no todos los países sustentaban sus regímenes en criterios oligárquicos, ya que, mientras algunos efectivamente recurrían a ellos en el ejercicio del poder, otros más se habían encaminado hacia un proceso de modernización política. ${ }^{29}$

esfuerzo colectivo en el que participaron Silvia Dutrénit, Javier Rodríguez, Mónica Toussaint y Johanna von Grafenstein. El trabajo que realizamos grupalmente se enfocaba al estudio de siete paises (Argentina, Bolivia, Brasil, Chile, México, Perú y Uruguay) y se encaminaba justamente a la búsqueda de los vínculos que existian entre la recesión de la economía y los cambios políticos. El resultado se discutió en un seminario organizado en 1986 por el Instituto Latinoamericano de Estudios Trasnacionales y actualmente se encuentra en prensa. Huelga decir que asumimos la responsabilidad por la forma en que aquí se presenten planteamientos cuya paternidad corresponde a varias personas.

27 Para recuperar las características de los acontecimientos de orden político que se sucedieron en los paises latinoamericanos al iniciarse la década de los treinta, además de las historias nacionales y de los estudios de caso, se puede obtener un buen resumen en Tulio Halperin Donghi, op. cit., pp. 336-437.

${ }^{26}$ Cfr. Silvia Dutrénit y otros, La crisis de 1929 $y$ los cambios políticos en América Latina, conAcult /Alianza/Grijalbo, México (en prensa), p. 9 (Serie Los Noventa).

${ }^{29}$ Recurriendo nuevamente a nuestro ejemplo, en el primer caso se encontrarian Bolivia, Brasil y Perú, mientras que en la segunda siruación estarían Argentina, Chile, México y Unuguay. Cfr. Silvia Dutrénit y otros, op. cit.
Frente a tal panorama resulta difícil asociar la descomposición del llamado Estado oligárquico exclusivamente con la depresión u homologar un proceso histórico que se fue dando en cada lugar de acuerdo a lógicas específicas, con ritmos diversos y en diferentes momentos.

Ahora bien, dado que nuestro planteamiento resalta la continuidad, ¿cómo se explican la serie de golpes de Estado y problemas del momento? Se necesitaría una gran miopía para pretender que todo seguía igual y que la ola de asonadas militares o civiles que recorrieron al continente fueron producto de una coincidencia; sin embargo, desde nuestra perspectiva tales situaciones se debieron a los reajustes que tuvieron lugar en el sistema político de la mayoría de los países $y$, como decíamos líneas arriba, en general no significaron cambios profundos en las formas estatales imperantes para entonces.

Lo que podría tomarse como una mera discusión semántica es en realidad un problema de fondo que remite a interpretaciones distintas del periodo y que tiene que ver entre otras cosas con las dificultades que conlleva el concepto de Estado, al cual, a pesar de, o quizá por, la cantidad de reflexiones que ha motivado, sigue moviéndose en un terreno bastante escurridizo y poco claro. Asi, las diferencias que existen entre los varios niveles involucrados en el ámbito de lo político no siempre resultan evidentes y se hace uso indistintamente de conceptos como Estado o sistema político aun cuando cada uno de ellos remita a distintos aspectos de la realidad. ${ }^{30}$

${ }^{30}$ Esta aparente intercambiabilidad de conceptos que en realidad son diferentes (y que podría 
En el caso concreto del Estado oligárquico, que es el que por el momento nos interesa, la situación se agrava, pues más allá de las dificultades que implica definirlo como una forma estatal y no otra cosa, ${ }^{31}$ el contenido histórico del que se le ha dotado va en más de una dirección. El primer problema pues, consiste en establecer lo que entendemos por este concepto. Como decíamos, optamos por considerarlo una forma de Estado en la que la estructura de poder se organiza de arriba para abajo y en la que aun cuando algunas veces se simulen principios demucráticos sigue imperando una especie de autocracia. ${ }^{32}$ Las pequeñas dimensiones y escasa o nula apertura del grupo que en este contexto detenta el poder se engloban bajo el término oligarquía, el cual, es también problemático, ya que se ha convertido en parte de un discurso que lo integra como un juicio de valor negativo $y$ deslegitimador, más que como una categoría analítica. ${ }^{33}$

incluir otras nociones como régimen o gobierno) tiene que ver con una esencia común a todos ellos: el ejercicio del poder. Cuando hablamos de Estado pensamos en un espacio específico de la sociedad desde el que se mantiene el control sobre esta, mientras que por sistema político entendemos la serie de relaciones que se han establecido para llevar adelante dicho control.

${ }^{31}$ Quizá si tomáramos la tipología que ofrece Poulantzas, en lugar de pensar que se trata de una forma de Estado, hablariamos de una forma de regimen. Cfr. Nicos Poulantzas, Poder político y clases sociales en el estado capitalista, Siglo XXI, México, 1975, pp. 176-197.

${ }^{32}$ Adoptamos la idea de Heller de que las formas del Estado van a estar determinadas por la manera en que se distribuye el poder y que en principio las dos formas fundamentales $y$ antagónicas se basan en la democracia por un lado y en la autocracia por el otro. Cfr. Hermann Heller, Teoría del Estado, Fondo de Cultura Económica, México, 1987, pp. 265-267.
De hecho, el carácter peyorativo que acompaña a la definición de oligarquía se remonta en el tiempo y aunque esta característica se relaciona con lo que en sentido estricto define la noción: un gobiemo de pocos, también se acentúa porque a diferencia de otros términos de la misma familia como monarquía o democracia, que remiten sobre todo a cierto tipo de instituciones, el de oligarquía se aparta del plano institucional y hace énfasis en un hecho: el poder supremo recae en un pequeño grupo de personas tendencialmente cerrado, unido por vínculos sanguíneos, de interés o de otro tipo y que gozando de privilegios particulares hace uso de todos los medios que están a su alcance para permanecer en el poder. ${ }^{34}$

El estado latinoamericano que nació después de la independencia estuvo en general rodeado de todas estas características ${ }^{35}$ pero a la vez, se expresó en

${ }^{33}$ François Bourricaud, "El ocaso de la oligarquía y la sobrevivencia del hombre oligárquico", en Aportes, núm. 4, abril de 1967, París.

${ }^{34}$ Norberto Bobbio y Nicola Matteucci (dir.), Diccionario de política L-Z, Siglo XXI, México, 1986, pp. 1118-1119.

"Se ha hecho hincapié en el carácter patrimonial de las formas de dominación que rigieron bajo el Estado oligárquico, carácter que en última instancia se reflejo en el surgimiento de líderes político-militares que de alguna manera reproducian la imagen del hacendado en el recién creado ámbito nacional y que dejaban a los escasos partidos de la época prácticamente sin ninguna posibilidad de participación real. Los caudillos que surgieron y se impusieron dentro de este marco basaban buena parte de su fuerza en estrategias de favores y lealtades que recuerdan al señor patrimonial y en general se mostraban incapaces de superar el autoritarismo y personalismo propios del mismo. Los intermediarios a los que recurrian en el ejercicio del poder distaban mucho del burócrata weberiano y carecian de un sentido de cuerpo, ya que, aun cuando la oligar- 
diversos tipos de sistema político que, de acuerdo con el país del que se trataba, generaron marcos jurídico-institucionales propios y relaciones de poder también diferenciadas. Así pues, lo que proponemos es que la serie de momentos disruptivos que se vivieron alrededor de 1930 deben ubicarse en este nivel, dentro del cual, se pueden hacer ajustes que no necesariamente alteran la forma estatal adoptada.

Para resumir nuestras ideas en torno a este tema diriamos que la relación entre los acontecimientos políticos que sacudieron al continente hacia el cambio de década y la crisis económica en la que se vio sumido el mundo después de 1929 no es tan mecánica como a veces se ha pensado. Dos son los problemas que intentamos definir al respecto: el primero remite a la confusión entre dos niveles de la realidad que han sido recuperados por la teoría de manera diferenciada, forma de Estado y sistema político y sobre los cuales ya hemos abundado. El segundo tiene que ver con la causalidad de los cambios ocurridos, ya que aun aceptando que fueron reajustes en el sistema político, habría que determinar el peso que en ellos tuvo la crisis. Desde nuestro punto de vista esta última fue un simple catalizador que no engendro efectos novedosos sino que aceleró procesos y proyectos ya existentes. ${ }^{36}$ En otras palabras, la serie de transformaciones

quía no controlara todos los resortes de la administración, como a veces se cree, los funcionarios tendian a considerarse como feudatarios al servicio de un individuo, una familia o un clan. Cfr. François Bourricaud, op. cit, pp. 12-23, y Octavio Ianni, op. cit, Pp. 72-83.

36 Cfr. Silvia Dutrénit y otros, op. cit. que tuvieron lugar en cada país, más o menos violentas, más o menos profundas, se originaron a partir de contradicciones que resultaron de un desarrollo histórico particular y que la crisis, en todo caso, se encargó de acentuar.

Finalizaríamos las breves reflexiones aquí expuestas preguntándonos si sigue siendo válido asignarle a la recesión de 1929 el papel protagónico que se le ha otorgado dentro de la historia latinoamericana. En principio y con base en todo lo dicho, nos inclinaríamos por cambiar este enfoque y plantearíamos la necesidad de explorar nuevas hipótesis que rescaten los procesos de larga duración presentes en todos los países del área, ${ }^{37}$ tanto para la década de los treinta como para otros momentos de nuestra historia. Creemos que es la combinación de tales procesos con coyunturas específicas, como pudo haber sido la crisis de 1929 , la que nos permite ubicar en su cabal dimensión los cambios y las continuidades vividas. Esta alternativa implica construir la globalidad con base en la particularidad y remite al análisis de los casos concretos, camino que, por lo demás, nos parece indispensable seguir si deseamos acercarnos a un objeto de estudiotan complejo y heterogéneocomo es América Latina.

México, D.F., enero de 1989.

${ }^{37}$ Es justamente la dimensión estructural, que aquí identificamos con los procesos de larga duración, la que puede escaparse cuando interpretamos la historia continental en funcion de paradigmas generales y olvidamos que cada uno de los paises es un mundo que ha producido situaciones especificas y que solo se entienden en conjunto si se utiliza a la diversidad como eje. 